\title{
Profiling Analysis Reveals the Crucial Role of the Endogenous Peptides in Bladder Cancer Progression
}

This article was published in the following Dove Press journal: OncoTargets and Therapy

\begin{abstract}
Weijian Li, I,* Yang Zhang, ${ }^{1,2, *}$ Youjian Li, ${ }^{1,3, *}$ Yuepeng Cao, 'Jun Zhou,' Zhongxu Sun, ' Wanke Wu, ${ }^{5}$ Xiaofang Tan, ${ }^{5}$ Yang Shao, ${ }^{5}$ Kaipeng Xie, ${ }^{5,6}$ Xiang Yan ${ }^{1,2}$

'Department of Nephrology and Urology, The Children's Hospital, Zhejiang University School of Medicine, National Clinical Research Center for Child Health, Hangzhou, People's Republic of China; ${ }^{2}$ Department of Urology, Drum Tower Hospital, Medical School of Nanjing University, Institute of Urology, Nanjing

University, Nanjing, People's Republic of China;

${ }^{3}$ Department of Urology Surgery, The People's Hospital of Xuancheng City, Xuancheng,

People's Republic of China; ${ }^{4}$ Department of Critical Care Medicine, Jiangsu Cancer Hospital, Jiangsu Institute of Cancer Research, Nanjing Medical University Affiliated Cancer Hospital, Nanjing, People's Republic of China; ${ }^{5} \mathrm{Nanjing}$ Maternity and Child Health Care Institute,

Women's Hospital of Nanjing Medical

University, Nanjing Maternity and Child Health

Care Hospital, The Affiliated Obstetrics and

Gynaecology Hospital of Nanjing Medical

University, Nanjing, People's Republic of China;

${ }^{6}$ Department of Women's Health Care, The

Affiliated Obstetrics and Gynaecology Hospital

of Nanjing Medical University, Nanjing

Maternity and Child Health Care Hospital,

Nanjing, People's Republic of China

*These authors contributed equally to this work
\end{abstract}

Correspondence: Xiang Yan

Department of Nephrology and Urology, The

Children's Hospital, Zhejiang University

School of Medicine, National Clinical Research

Center for Child Health, Hangzhou, People's

Republic of China

Email yanxiang@zju.edu.cn

Kaipeng Xie

Nanjing Maternity and Child Health Care Institute, Women's Hospital of Nanjing Medical University, Nanjing Maternity and Child Health Care Hospital, The Affiliated

Obstetrics and Gynecology Hospital of

Nanjing Medical University, Nanjing 210004,

People's Republic of China

Tel/Fax +86-25-5222-6264

Email kaipengxienjmu@I63.com
Background: Peptide drugs provide promising regimes in bladder cancer. In order to identify potential bioactive peptides involved in bladder cancer, we performed the present study.

Methods: Liquid chromatography/mass spectrometry assay was used to compare the endogenous peptides between bladder cancer and normal control. The potential biological functions of these dysregulated peptides are assessed by GO analysis and KEGG pathway analysis of their precursors. The SMART and UniProt databases are used to identify the sequences of the dysregulated peptides located in the functional domains. The Open Targets Platform database was used to investigate the precursors related to metabolic diseases.

Results: A total of 9 up-regulated peptides and 110 down-regulated peptides in bladder cancer compared with normal control were identified (fold change $>1.2, P<0.05$ ). The MW of these dysregulated peptides ranged from $500 \mathrm{Da}$ to $2500 \mathrm{Da}$ and the MW of all identified peptides was below $3500 \mathrm{Da}$. The GO and KEGG pathway analysis indicated that these dysregulated peptides could play an important role in bladder cancer. Our further analysis revealed that ${ }^{45}$ HFNPRFNAHGDAN ${ }^{57}$ derived from LGALS1 and those peptides derived from P4HB and SERPINA1 might be the promising diagnostic biomarkers and therapeutic targets of bladder cancer.

Conclusion: In the present study, we have identified the profile of the peptides significantly dysregulated in bladder cancer. Moreover, using bioinformatic analysis, we found the peptides derived from LGALS1, P4HB and SERPINA1 could be the promising diagnostic biomarkers and therapeutic targets of bladder cancer.

Keywords: peptide, therapeutic target, progression, bladder cancer

\section{Introduction}

Bladder cancer $(\mathrm{BC})$ is the ninth most common cancer worldwide, including approximately 430,000 incident cases and 165,000 attributable deaths annually worldwide. ${ }^{1,2}$ It is a complex disease associated with high morbidity and mortality without effective therapy. $^{3}$ Approximately $80 \%$ of $\mathrm{BC}$ are classified as non-muscle invasive $\mathrm{BC}$ (NMIBC) depending on the degree of tumor infiltration in the vesical wall, while the remainder are muscle invasive $\mathrm{BC}(\mathrm{MIBC}){ }^{4}$ Patients with NMIBC have to undergo invasive cystoscopy regularly after TURBT to detect tumor recurrence. ${ }^{5}$ Nevertheless, up to $70 \%$ of NMIBC patients still experience disease recurrence and progression. ${ }^{6}$ Furthermore, patients have to undergo radical cystectomy or chemotherapy in case of tumor recurrence and progression, which imposes a great deal of pain and injury on them. ${ }^{7,8}$ Therefore, in order to prevent BC progression more effectively, it is urgent to reveal the potential mechanisms in the progression of $\mathrm{BC}$. 
Peptide is a type of organic compound produced by endocrine glandular tissues or organs, containing 3-50 amino acids. ${ }^{9}$ As an important role, peptide participates in almost all physiological activities, including cell differentiation, immune regulation and, especially, tumor formation. ${ }^{10}$ In recent years, the application of peptides in the diagnosis and treatment of $\mathrm{BC}$ has aroused increasing interest. Based on the different metabolomic characteristics, two urinary peptides (AspAspGlyTrp and GlyCysAlaLys) were developed as early BC diagnostic biomarkers. ${ }^{11}$

Maria Frantzi et al exploits two urine-based peptide biomarker panels for detecting primary and recurrent urothelial BC. ${ }^{4}$ Some other endogenous peptides such as Sixtransmembrane epithelial antigen of the prostate (STEAP), ${ }^{12}$ antimicrobial peptide magainin II, ${ }^{13}$ DEP domain containing 1 (DEPDC1) and M-phase phosphoprotein 1 (MPHOSPH1) ${ }^{14}$ are promising peptides in the treatment of $\mathrm{BC}$.

However, due to technical limitations, the mechanisms of peptides in the pathogenesis of $\mathrm{BC}$ have not been fully studied in the past decades. With the technical development of proteomics, we have the opportunity to further investigate the role of endogenous peptides in disease. ${ }^{15}$ Using peptidomics technology, a group of peptides have been identified to function in cells. ${ }^{16,17}$ Therefore, as a new field focusing on the function of endogenous peptides, peptidomics has emerged, which attracted increasing interests of researchers recently. ${ }^{18}$ However, there is still very limited information on differentially expressed peptides between normal urothelium and $\mathrm{BC}$ tissue. Therefore, it is of great importance to perform an in-depth peptidomic analysis to reveal the mechanism of $\mathrm{BC}$ progression.

In the present study, we identified the endogenous peptides that differentially expressed in BC. Furthermore, we analyzed the basic characteristic, cleavage sites patterns of these dysregulated peptides. GO analysis, KEGG pathway analysis, PPI analysis and functional domain analysis of the identified endogenous peptides were also conducted. We hope that our work could help to reveal the mechanism of bladder cancer progression from the aspect of peptidomics.

\section{Materials and Methods}

\section{Patients and Tissue Specimens}

The present study was conducted according to the recommendation of the Declaration of Helsinki and was approved by the Ethics Committee of Nanjing Drum Tower Hospital. Patients with a history of other cancers and any preoperative chemotherapy or radiotherapy were excluded. BC tissues and adjacent normal control tissues were collected from patients undergoing radical cystectomy. Finally, a total of 3 highgrade $\mathrm{BC}$ tissues and the matched normal control tissues were collected (Table 1). All collected samples were placed in frozen storage tubes and immediately snap-frozen in liquid nitrogen and stored at $-80^{\circ} \mathrm{C}$ until use. Each patient has signed the informed consent before we collected the samples.

\section{Peptides Extraction and Purification}

All collected samples were added to the protease inhibitor mixture (Complete Mini EDTA-free, Roche, Basel, Switzerland) after isotonic PBS washing. The tissue specimen was cut into pieces and then ultrasonically homogenized for 20 min. Then, we added $20 \%$ acetonitrile to the lysate to block the connection between the proteins and peptides. Then, the samples were centrifuged at $12,000 \mathrm{~g}$ in the condition of $4^{\circ} \mathrm{C}$ for 15 min to obtain the supernatant. According to the manufacturer's instructions, the samples were centrifuged by AMICON 10 $\mathrm{kDa}$ molecular weight cut off (MWCO) centrifuge filter (Millipore). Then, the supernatant was filtered through a molecular filter, with the flow-through containing the peptides. Afterward, the BCA method was used to measure the concentration of the supernatant peptides. Lastly, supernatants were vacuum-dried by a Speed-vac system (RVC 2-18) and immediately frozen at $-80^{\circ} \mathrm{C}$ for subsequent experiments.

\section{TMT Labeling and LC-MS/MS Analysis}

The freeze-dried peptide was dissolved in $0.1 \%$ formic acid and the solution was filtered through a $0.45-\mu \mathrm{m}$ membrane. The filtrate was reduced with $10 \mathrm{mM}$ DTT at $60^{\circ} \mathrm{C}$ for 1 $\mathrm{h}$ and afterwards alkylated via $50 \mathrm{mM}$ iodoacetamide at room temperature in the dark for $45 \mathrm{~min}$. Next, the peptides were desalted and dried, followed by the manufacturer's

Table I Clinical Characteristic of the BC Patients

\begin{tabular}{|l|l|l|l|l|l|l|}
\hline Characteristics & Age $\mathbf{( y )}$ & Grade & Gender & Tumor Size(cm) & T stage & Muscle Invasion \\
\hline Patient I & 58 & High & Male & 3 & T2 & Yes \\
Patient 2 & 53 & High & Female & 2 & T3 & Yes \\
Patient 3 & 67 & High & Male & 3 & T2 & Yes \\
\hline
\end{tabular}


recommendation, $5 \mu \mathrm{L}$ of the TMT reagent (TMT 6-plex Label Reagent; Thermo Fisher Scientific, Waltham, MA, USA) were used to label with each $20 \mu \mathrm{g}$ of the samples. Afterwards, the peptides labeled by TMT reagent were frozen at $-80^{\circ} \mathrm{C}$ for further liquid chromatography (LC)tandem mass spectrometry (MS/MS) analysis.

The separation was carried out by NanoAcuity ultrahigh pressure nanoscale upgrading liquid chromatography system. Liquid phase A is $0.1 \%$ formic acid-aqueous solution, and $\mathrm{B}$ solution is $0.1 \%$ formic acid-acetonitrile solution. The sample was dissolved in $200 \mu \mathrm{L}$ A phase. After 2 $\mu \mathrm{L}$ sample was absorbed by automatic injector, the sample was transmitted to the trap column at $10 \mu \mathrm{L} / \mathrm{min}$ flow rate for 2 minutes. The samples on the capture column were separated by chromatography on the analytical column with a flow rate of $300 \mathrm{~mL} / \mathrm{min}$. The spray voltage of Q-Exative mass spectrometer ion source is $2.0 \mathrm{kV}$, and the heating capillary is set to 300 . The data-dependent mode is used to automatically switch the collection between MS and MS/MS. The full-scan MS uses Orbitrap for a first-level scan with a scan range of $350 \mathrm{~m}$ 1600 and a resolution set to 70,000 ( $\mathrm{mz} \mathrm{200).} \mathrm{The} \mathrm{max-}$ imum introduction time of the ion is $50 \mathrm{Ms}$, the automatic gain control (Automatic gain control, AGC) is set to $5 \times 10^{5}$, and then the top 10 parent ions which meet the conditions of cascade (MS/MS) fragmentation were broken by high energy C-trap dissociation (HCD) and scanned with orbitrap. The scanning resolution was set to 17,500 . The scan range is controlled automatically according to the mother-child mass-charge ratio, and the lowest scan range is fixed at $\mathrm{m} / \mathrm{z}=100$, up to 2000 . The minimum ionic strength for MS/MS is set to 500, 000. The maximum ion introduction time is $100 \mathrm{Ms}$ in $\mathrm{MS} / \mathrm{MS}$, the AGC control is set to $1.0 \times 10^{5}$, and the parent ion selection window is set to 2 Dalton. The 2,3,4 charge number ions are collected by $\mathrm{MS} / \mathrm{MS}$, and the dynamic exclusion is set to remove 30 seconds, $30 \%$ collision energy after one MS/MS, per parent ion in 10 seconds.

\section{Peptide Quantification}

We performed MS analysis according to the previous study. ${ }^{19-21}$ We injected the samples into the LTQOrbitrap Velos mass spectrometer. Full-scan analysis was performed over the $\mathrm{m} / \mathrm{z}$ range $400-5000$ at 3 spectra/s. We, respectively, maintained the capillary voltage and cone voltage at $3.9 \mathrm{kV}$ and $40 \mathrm{~V}$. In mass spectrometry analysis, 2000 single spectra were accumulated from 10 random positions on each sample, and each position was illuminated with 200 laser pulses.

The tolerance to the precursor ion mass was $10 \mathrm{ppm}$, the fragment tolerance was $0.05 \mathrm{Da}$ and for miss cleavage, a single amino acid. In particular, we conducted an automatic decoy database search in Mascot via selecting the decoy checkbox where a random database sequence was generated and the raw spectrum as well as the real database was tested. In order to reduce the probability of false peptide identification, we applied the manufacturer's recommended isotope correction factors, and only the peptides with significance scores ( $\geq 20$ ) at the $99 \%$ confidence interval by a Mascot probability analysis greater than "identity" were counted as identified. In the search, all peptides contained are at least 6 amino acids in length. We also used PEAKS software to search the databases via MS/MS spectral data.

\section{Bioinformatics Analysis}

For further research, the molecular weight (MW) and isoelectric point $(\mathrm{pI})$ of each peptide were calculated using the online tool pI/MW (http://web.expasy.org/compute.pi/). We map the genes to the nodes of the Gene Ontology database and use GO (http://www.geneontology.org/) for functional enrichment analysis. The potential functions of these dysregulated peptide's precursors are mainly containing the following three categories: cellular component, biological process, and molecular function. KEGG pathway analysis was performed to predict biologic, putative biochemical and molecular functions of the selected peptides. The UniProt Database and SMART were applied to detect whether the dysregulated peptide sequences are located in the conservative domain structure of their precursor proteins. We used the Open Targets Platform database to reveal the relationship between the differentially expressed peptides and human disease. The protein interaction information of PPI network was constructed by using STRING database (v10, string-db.org). ${ }^{22,23}$ The precursor proteins of these differentially expressed peptides were searched in Homo sapiens of the STRING database, and the network interaction map was constructed based on the interaction information searched.

\section{Statistical Analysis}

The differences between groups were assessed by a Student's $t$-test and one-way ANOVA using the SPSS 20.0 software package (SPSS, Chicago, IL, USA). $P<$ 
0.05 was considered to indicate a significant difference. The threshold value | fold change $\mid>1.2$ was used to screen differentially expressed peptides. All experiments were performed in triplicate.

\section{Results}

\section{Identification of Differentially Expressed Peptides Between Bladder Cancer and Normal Control}

Endogenous peptides from the $\mathrm{BC}$ and normal control were directly analyzed by LC-MS/MS. Totally, 4408 non-redundant peptides have been identified. Among these peptides, we found that 119 peptides derived from 62 precursor proteins were significantly dysregulated, including 9 up-regulated peptides and 110 down-regulated peptides in $\mathrm{BC}$ compared with normal control ( $\mid$ fold change $\mid>1.2, P<0.05$ ). The dysregulated peptides are visualized in heat map (Figure 1A) and volcano plot (Figure 1B). In addition, Table 2 shows part of the differentially expressed peptides in $\mathrm{BC}$ tissues compared with normal control tissues.

\section{Characteristics and Cleavage Site Patterns of the Dysregulated Peptides}

Most peptides have molecular weights (MW) ranging from $500 \mathrm{Da}$ to $2500 \mathrm{Da}$ and the MW of all identified peptides was below $3500 \mathrm{Da}$ (Figure 2A). Furthermore, the pI distribution of the dysregulated peptides ranged from 3.4 to 12.3 (Figure 2B). Because the $\mathrm{pI}$ distribution is related to the MW distribution and the amino acid composition, we also investigated the distribution of the MW relative to the pI (Figure 2C).

Previous researches ${ }^{24,25}$ have proved that the regulation of the expression of peptides is associated with the enzymatic cleavage of the precursor proteins. Therefore, we analyzed the cleavage sites at the Nand C-terminals of the dysregulated peptides. As shown in Figure 2D, the top four most common cleavage sites included the amino acids ala (A), serine (S), lysine $(\mathrm{K})$ and leucine $(\mathrm{L})$. Meanwhile, we found that some dysregulated peptides derived from the same precursor protein. As shown in Figure 2E, the precursor proteins which more than one peptide shared were listed, and we found that SERPINA1 has the largest number of related peptides.
A

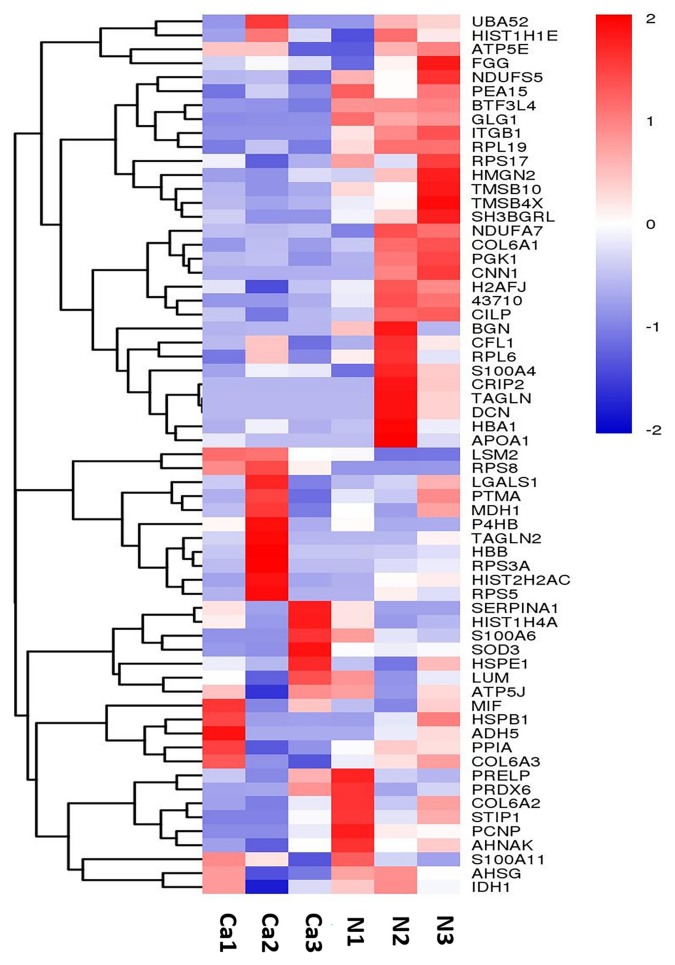

B

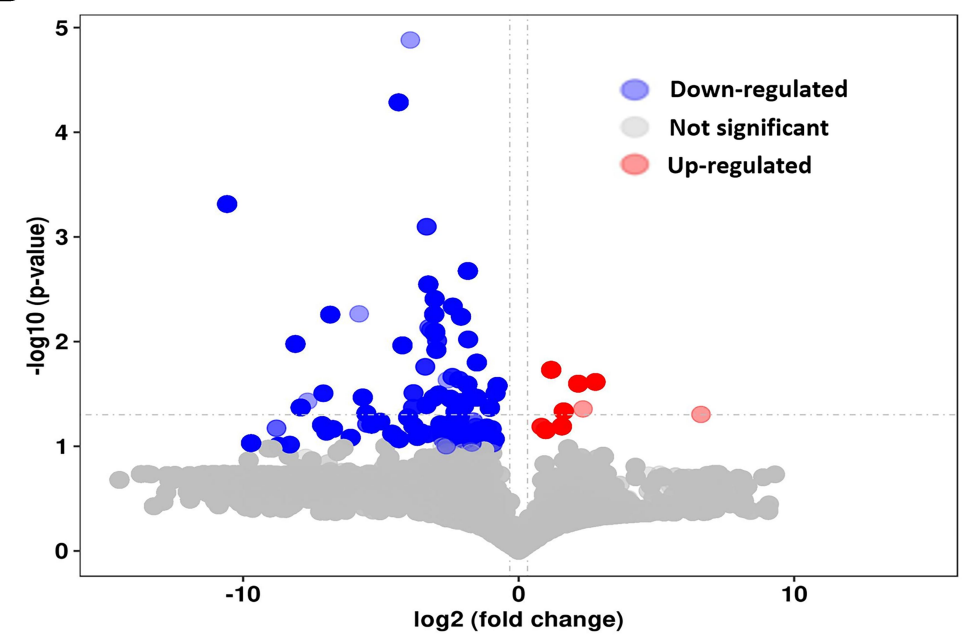

Figure I Differentially expressed peptides in bl3adder cancer compared with normal urothelium tissues. (A) Heatmap of expression profiles for the II9 dysregulated peptides containing 9 up-regulated peptides and 110 down-regulated peptides. (B) Volcano plots of the dysregulated peptides in BC. 
Table 2 Part of the Differently Expressed Peptides in Bladder Cancer Tissues Compared with Normal Urothelium Tissues

\begin{tabular}{|c|c|c|c|c|c|}
\hline Gene & Protein & \multirow[t]{2}{*}{ Sequence } & \multirow{2}{*}{$\begin{array}{l}\text { MW } \\
(k D a)\end{array}$} & \multirow{2}{*}{$\begin{array}{l}\text { Fold } \\
\text { Change }\end{array}$} & \multirow[t]{2}{*}{$P$-value } \\
\hline \multicolumn{2}{|c|}{ Up-Regulated Peptides } & & & & \\
\hline RPS8 & $40 \mathrm{~S}$ ribosomal protein $\mathrm{S} 8$ & YLRKIKARKGK & |360.7| & 98.19565075 & 0.04963442 \\
\hline SIOOA6 & Protein SI00-A6 & LDRNKDQEVNF & 1377.48 & 6.90802353 & 0.0242696 \\
\hline LSM2 & U6 snRNA-associated Sm-like protein LSm2 & LQDAARKEALQQKQ & 1626.83 & $5.0405 I 2325$ & 0.04398991 \\
\hline$H B B$ & $\begin{array}{l}\text { Hemoglobin subunit beta;LVV-hemorphin-7; } \\
\text { Spinorphin }\end{array}$ & KGTFATLSELHCDKLHVDPEN & 2354.62 & 4.478971853 & 0.02523424 \\
\hline HSPEI & 10 kDa heat shock protein, mitochondrial & FRDGDILGKYVD & I397.55 & 3.107810767 & $0.0462705 I$ \\
\hline$H B A I$ & Hemoglobin subunit alpha & SVSTVLTSKYR & 1240.42 & 2.962531037 & 0.03464964 \\
\hline HBAI & Hemoglobin subunit alpha & ASVSTVLTSKYR & 1311.50 & 2.267838831 & 0.01861224 \\
\hline SIOOAII & $\begin{array}{l}\text { Protein SI00-AI I;Protein SI00-AII, } \\
\text { N-terminally processed }\end{array}$ & FLKAVPSQKRT & 1274.53 & 1.977297757 & 0.02023438 \\
\hline HISTIHIE & Histone HI.4 & SETAPAAPAAPAPAEKTPVK & 1904.15 & 1.775721232 & 0.03494765 \\
\hline \multicolumn{6}{|c|}{ Down-regulated peptides } \\
\hline TMSB4X & $\begin{array}{l}\text { Thymosin beta-4;Hematopoietic system } \\
\text { regulatory peptide }\end{array}$ & SDKPDMAEIEKFDKSKLK & 2109.42 & 0.000652869 & 0.00048494 \\
\hline TAGLN & Transgelin & IIVQCGPDVGRPDRGRLG & 1908.21 & 0.00119247 & 0.02324176 \\
\hline FGG & Fibrinogen gamma chain & TYNPDESSKPNMIDA & 1681.79 & 0.002260979 & 0.02727634 \\
\hline PRELP & Prolargin & DLQHNRLSDGVFKPDTFHGLKN & 2538.81 & 0.0023698 & 0.02988005 \\
\hline PTMA & $\begin{array}{l}\text { Prothymosin alpha;Prothymosin alpha, } \\
\text { N-terminally processed;Thymosin alpha-I }\end{array}$ & SDAAVDTSSEITTKDLKEKKEVVEEAEN & 3066.28 & 0.003162826 & 0.01644275 \\
\hline MIF & Macrophage migration inhibitory factor & TQQLAQATGKPPQY & 1530.70 & $0.003639|7|$ & 0.02053066 \\
\hline SERPINAI & Alpha-I-antitrypsin;Short peptide from AAT & QNTKSPLFMGKVVNPTQ & 1889.20 & 0.0041546 & 0.04265418 \\
\hline ITGBI & Integrin beta-I & SAVTTVVNPKYEGK & 1492.69 & 0.004947969 & $0.037 \mid 3312$ \\
\hline SERPINAI & Alpha-I-antitrypsin;Short peptide from AAT & LRTLNQPDSQ & 1171.28 & $0.007 \mid 27744$ & 0.0267898 \\
\hline
\end{tabular}

Gene Ontology (GO) and KEGG Pathway Analysis of Peptide Precursors

GO and KEGG pathway analysis were performed to explore the potential functions of these dysregulated peptides and their precursor proteins. Cadherin binding, oxidoreductase activity. RNA binding, structural molecule activity and so on were the most highly enriched GO terms in molecular functions, whereas focal adhesion, extracellular matrix, extracellular exosome, collagen containing extracellular matrix and so on were the most highly enriched cellular component. Finally, in biological processes, the most highly enriched GO terms are translational initiation, mRNA catabolic process, protein targeting to ER and so on (Figure 3A).

As shown in Figure 3B, the KEGG pathway enrichment analysis indicates that Ribosome, Carbon metabolism, Glycolysis/Gluconeogenesis, Biosynthesis of amino acids, Systemic lupus erythematosus, Necroptosis, African trypanosomiasis, Pentose phosphate pathway, Fructose and mannose metabolism were the 10 most common pathways in which the differentially expressed peptides and their corresponding precursor proteins were involved in.

Furthermore, KEGG pathway analysis revealed that these dysregulated peptides are involved in oxidative phosphorylation. Oxidative phosphorylation was found to be a crucial pathway in cancer progression ${ }^{26,27}$ (Figure S1). Meanwhile, we found that these dysregulated peptides are involved in retrograde endocannabinoid signaling which have been proved to play an important role in multiple cancer progression ${ }^{28-30}$ (Figure S2). These results showed that the dysregulated peptides might play an important role in $\mathrm{BC}$.

\section{The Protein-Protein Interaction Network of Peptide Precursors}

Previous studies proved that the function of bioactive peptides is related to the function of their precursor proteins. ${ }^{31}$ Therefore, to further investigate the role of these dysregulated peptides in $\mathrm{BC}$, a protein-protein interaction (PPI) network was constructed based on the STRING database. As shown in Figure 4, UBA52, HSPE1, P4HB and RPS3A are 

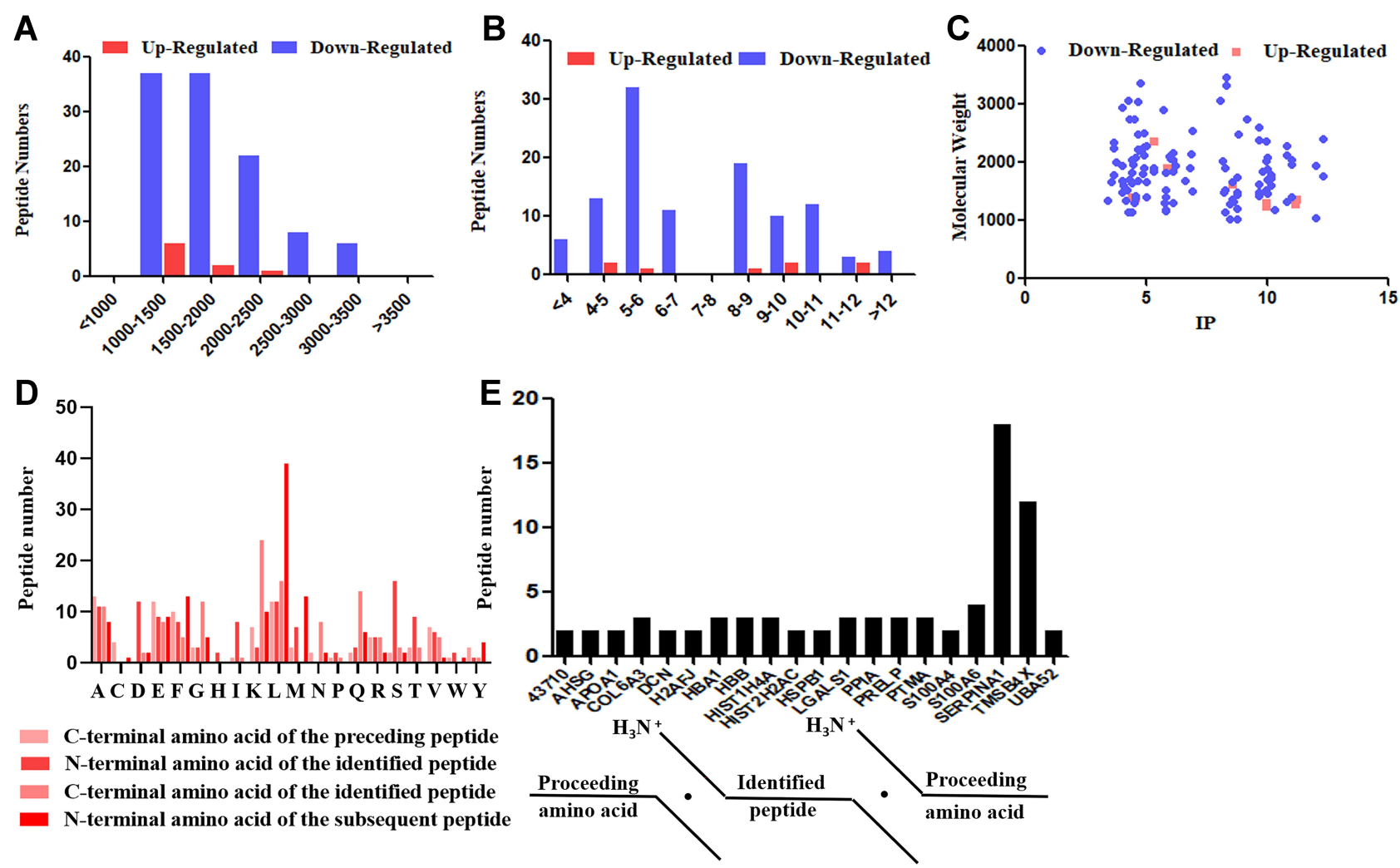

Figure 2 Basic features of differentially expressed peptides identified by LC-MS/MS. (A) Molecular weight (MW). (B) Isoelectric point (pl). (C) Scatter plot of MW versus pl. (D) Distribution of the four cleavage sites in the identified dysregulated peptides. (E) Peptides shared the same precursor proteins.

A

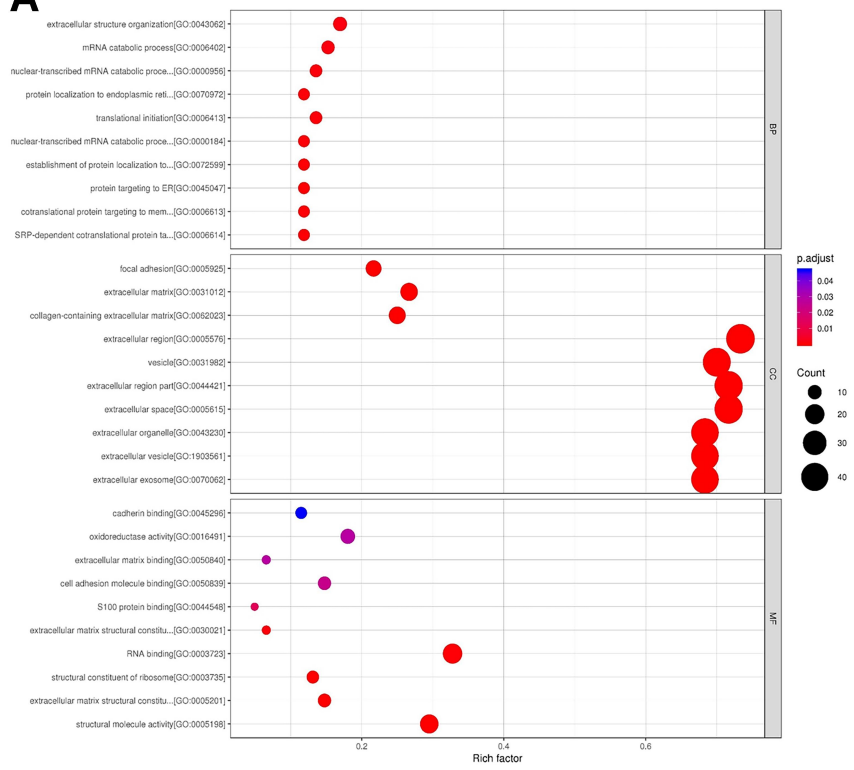

B

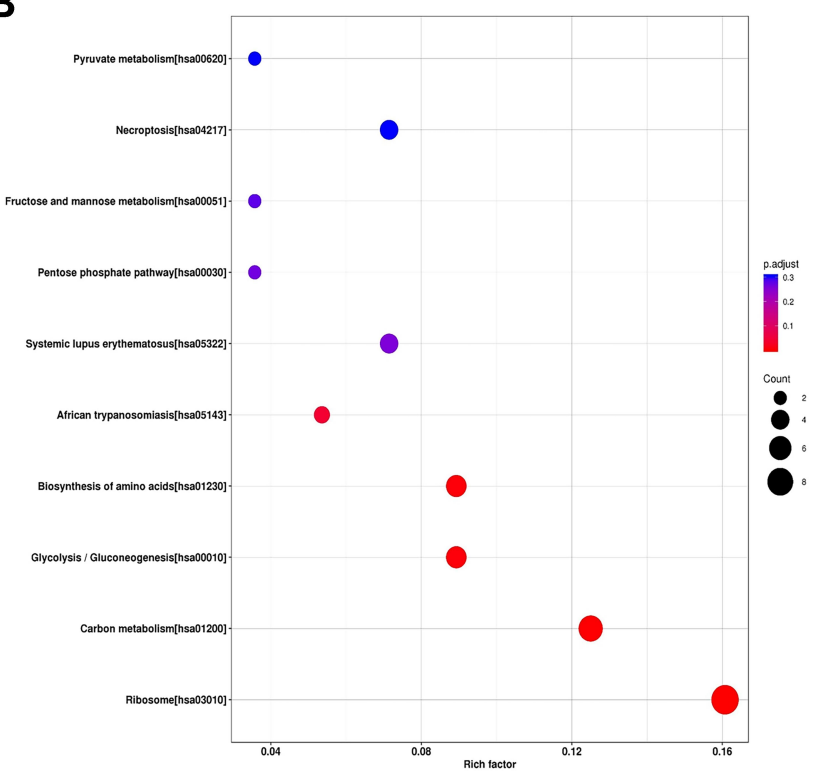

Figure 3 Gene ontology (GO) and KEGG pathways analysis of precursor proteins from which differentially expressed peptides were derived. (A) GO analysis of precursor proteins containing biological process categories, molecular function categories and cellular component categories. The horizontal coordinates in the diagram are the Rich factor values of the enrichment degree, and the vertical coordinates are GO Term. (B) KEGG pathways analysis of precursor proteins. The horizontal coordinates in the diagram are the Rich factor values of the enrichment degree, and the vertical coordinates are the KEGG Pathway information. 


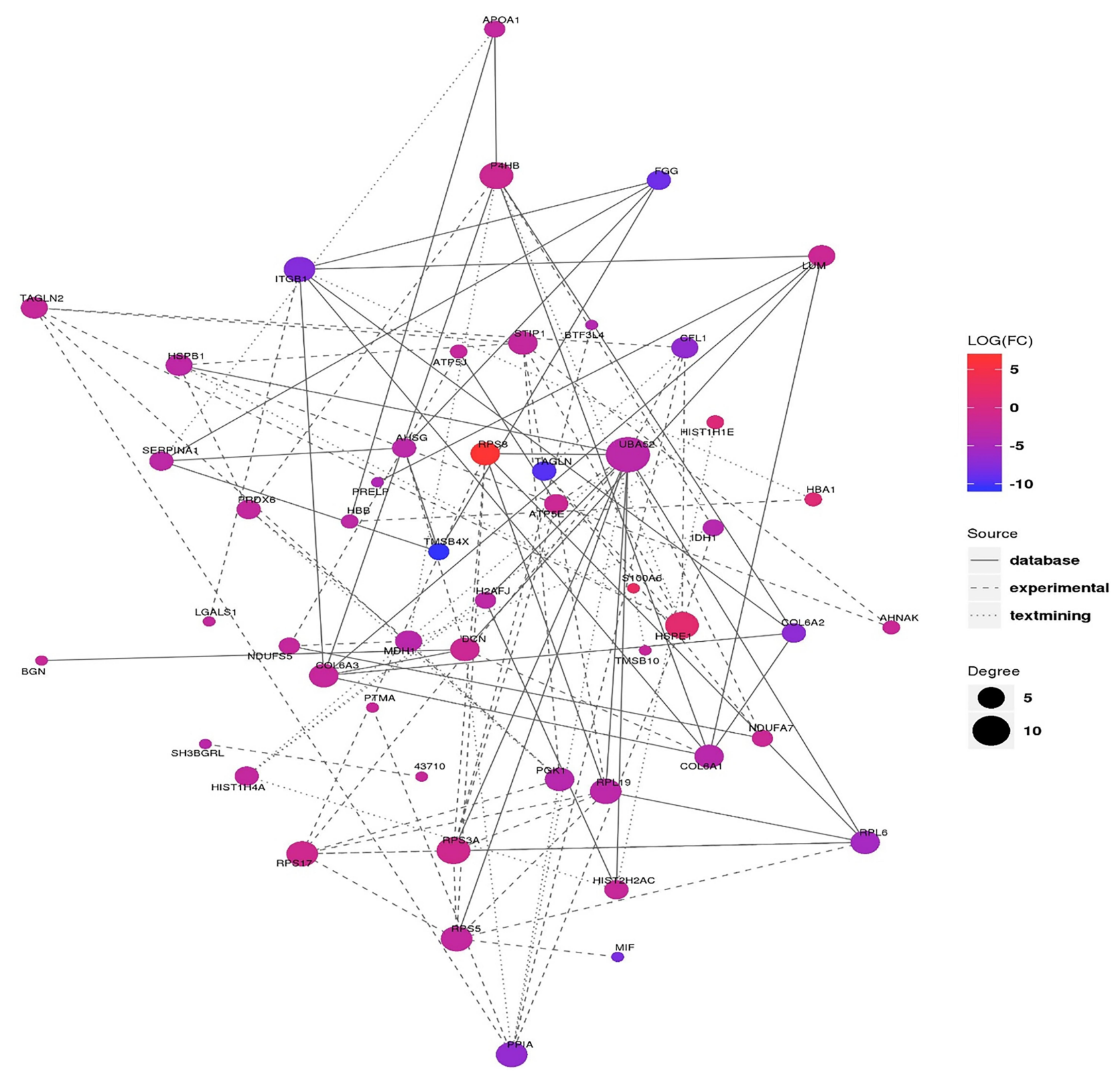

Figure 4 PPI network of altered peptide precursors. The color indicates the expression level of the differentially expressed protein, the red indicates the difference is upregulated, the blue indicates the difference is down-regulated, and the size of the circle indicates the connective degree. The types of connections represent the source of interaction relationships, the real lines represent interactions from databases, dashed lines represent interactions from experiments, and dots represent interactions from text mining.

the top four precursor proteins which got the largest number of interacting proteins.

\section{Putative Bioactive Peptides Associated with Bladder Cancer}

Meanwhile, peptides derived from the functional domains of their precursor protein were analyzed using the online tool SMART and UniProt database. Totally, 37 peptide sequences were located in the functional domains of their corresponding precursor proteins (Table 3). Furthermore, to reveal the potential peptides that play a role in $\mathrm{BC}$, the Open Targets Platform database was used to investigate protein precursors. As shown in Table 4, a total of 50 precursor proteins were considered to be related to urogenital neoplasm.

\section{Discussion}

In recent years, with the technical development of proteomics and related methodologies, endogenous peptides are 


\begin{tabular}{|c|c|c|}
\hline \multicolumn{2}{|c|}{ 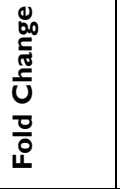 } & 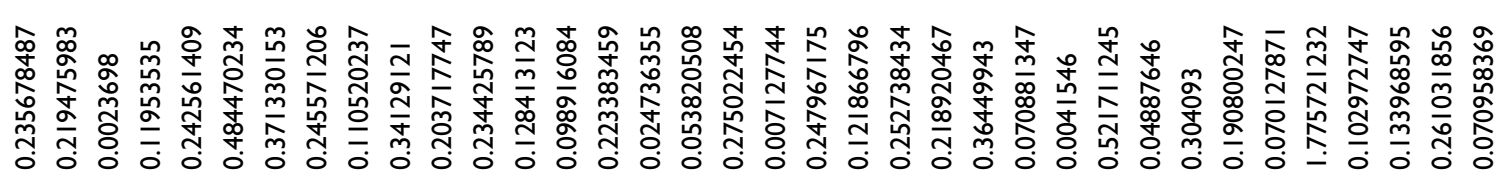 \\
\hline & 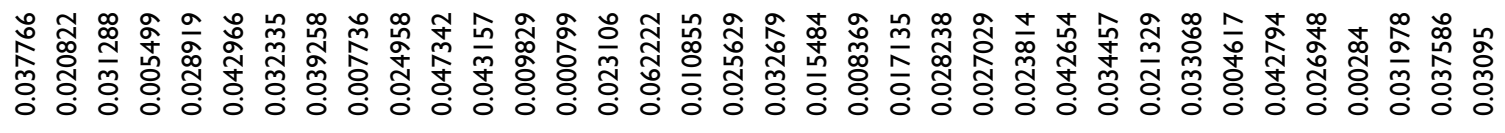 \\
\hline \multicolumn{2}{|l|}{ 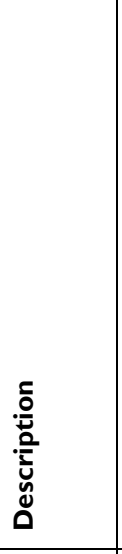 } & 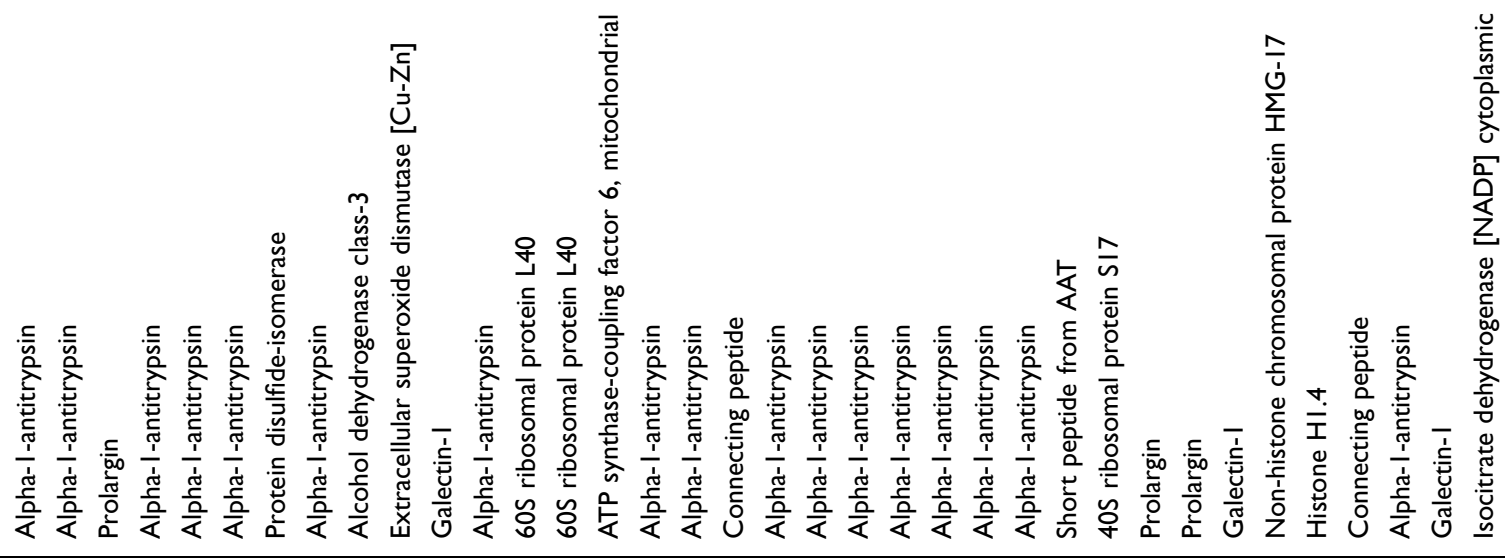 \\
\hline \multicolumn{2}{|l|}{ 芫 } & 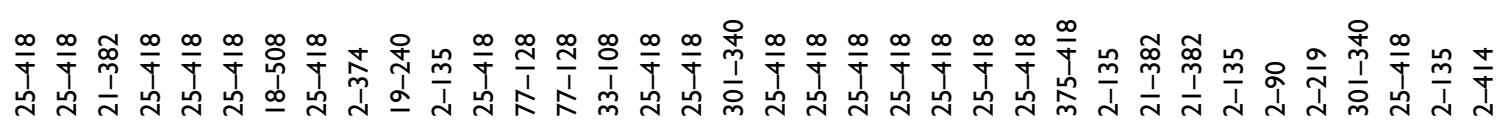 \\
\hline \multirow{2}{*}{ 雚 } & 胥 & 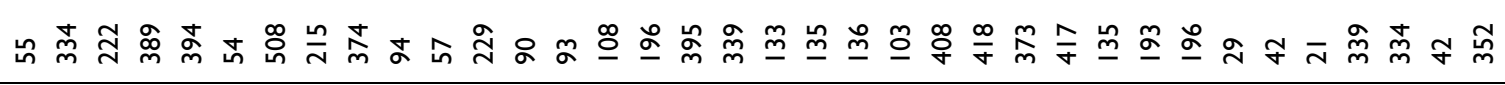 \\
\hline & 䔍 & 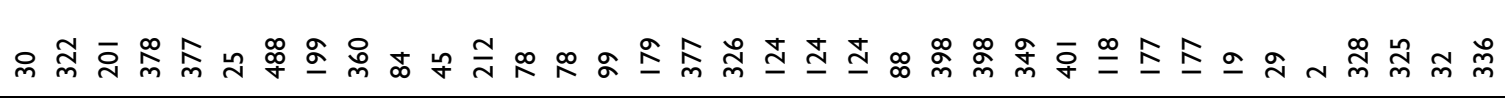 \\
\hline \multicolumn{2}{|l|}{ 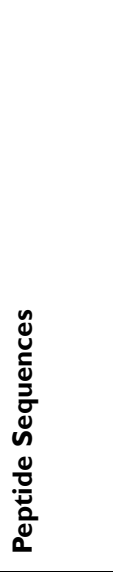 } & 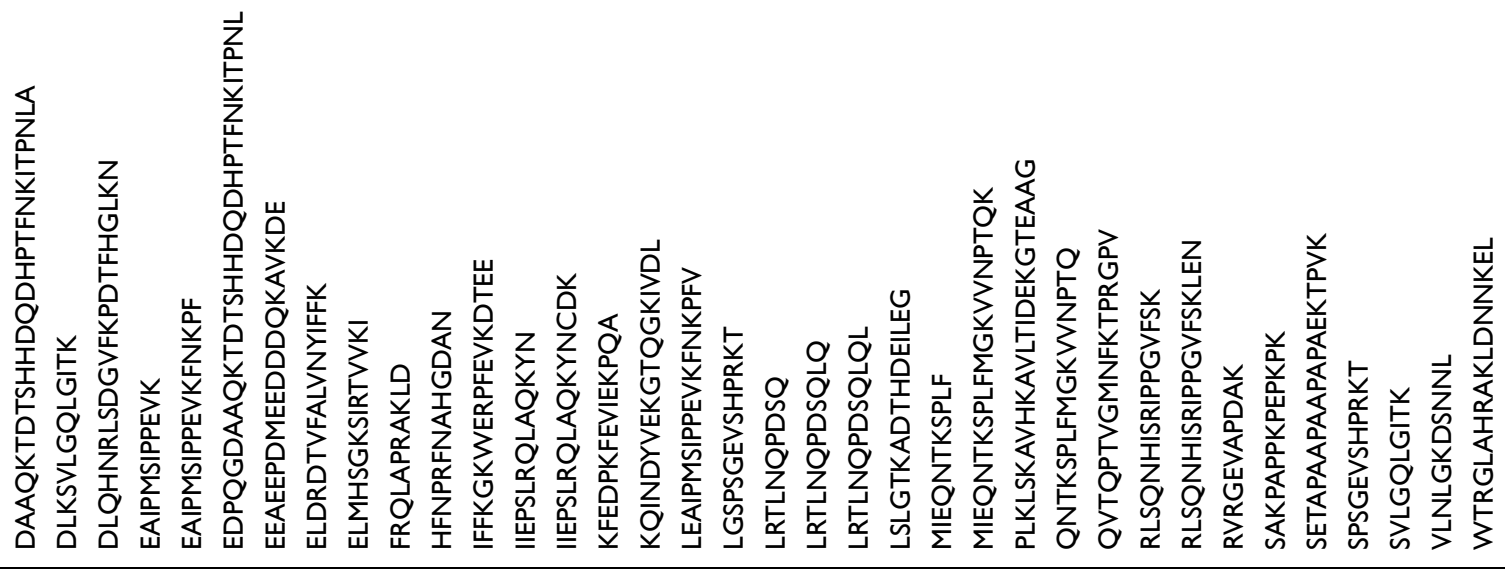 \\
\hline 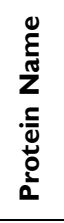 & & 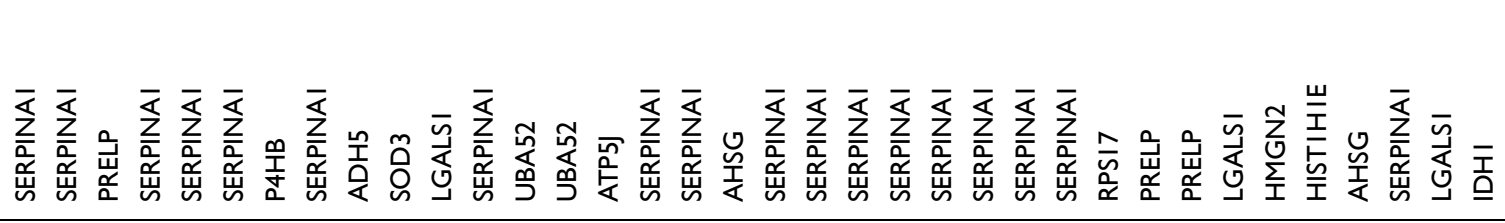 \\
\hline 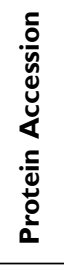 & & 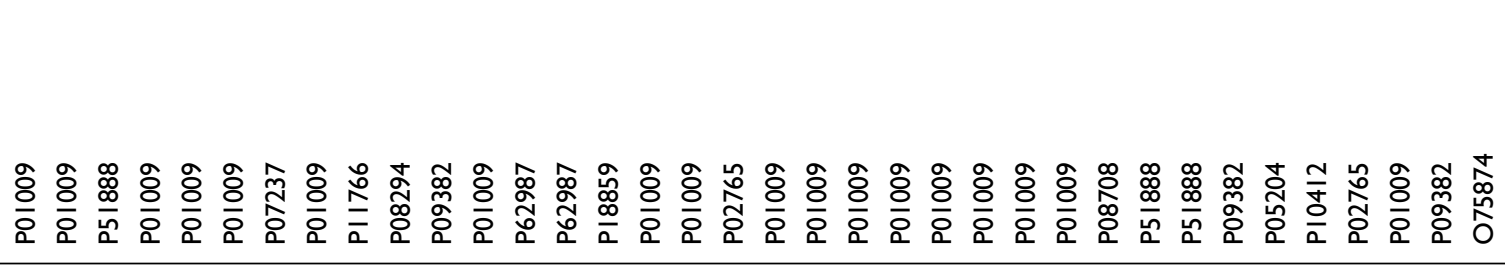 \\
\hline
\end{tabular}


Table 4 Protein Precursors and Identified Peptides Related to Urogenital Neoplasm

\begin{tabular}{|c|c|c|c|}
\hline Protein Name & Association Score & Peptide Numbers & Target Gene Name \\
\hline IDHI & I & I & Isocitrate dehydrogenase (NADP(+)) I, cytosolic \\
\hline NDUFA7 & I & 1 & NADH:ubiquinone oxidoreductase subunit A7 \\
\hline NDUFS5 & 1 & 1 & NADH:ubiquinone oxidoreductase subunit S5 \\
\hline UBA52 & 0.81199992 & I & Ubiquitin A-52 residue ribosomal protein fusion product I \\
\hline HIST2H2AC & 0.8006457 & 2 & Histone cluster $2 \mathrm{H} 2 \mathrm{~A}$ family member c \\
\hline RPLI9 & 0.79641324 & I & Ribosomal protein LI9 \\
\hline ITGBI & 0.76437047 & 1 & Integrin subunit beta I \\
\hline HISTIHIE & $0.7637 \mid 103$ & 1 & Histone cluster I HI family member e \\
\hline FGG & 0.75537863 & I & Fibrinogen gamma chain \\
\hline $\mathrm{H} 2 \mathrm{AFJ}$ & 0.75382293 & 2 & H2A histone family member $\mathrm{J}$ \\
\hline RPS3A & 0.73017717 & 1 & Ribosomal protein S3A \\
\hline APOAI & 0.61937796 & 2 & Apolipoprotein AI \\
\hline $\mathrm{HBB}$ & 0.46185019 & 3 & Hemoglobin subunit beta \\
\hline HBAI & $0.4594274 I$ & 3 & hemoglobin subunit alpha I \\
\hline $\mathrm{P} 4 \mathrm{HB}$ & 0.42665308 & 1 & Prolyl 4-hydroxylase subunit beta \\
\hline COL6AI & 0.425827 & 2 & Collagen type VI alpha I chain \\
\hline COL6A3 & 0.4070895 & 3 & Collagen type VI alpha 3 chain \\
\hline COL6A2 & 0.40516103 & I & Collagen type VI alpha 2 chain \\
\hline PGKI & 0.37178884 & I & Phosphoglycerate kinase I \\
\hline STIPI & 0.31365796 & I & Stress induced phosphoprotein I \\
\hline PPIA & 0.31318047 & 3 & Peptidylprolyl isomerase A \\
\hline PRELP & 0.29236622 & 3 & Proline and arginine rich end leucine rich repeat protein \\
\hline $\mathrm{MDHI}$ & 0.25592816 & I & Malate dehydrogenase I \\
\hline LGALSI & 0.24935391 & 3 & Galectin I \\
\hline SI00A6 & 0.24904395 & I & SI00 calcium binding protein A6 \\
\hline SI00A4 & 0.24179143 & I & SI00 calcium binding protein A4 \\
\hline SIOOAII & 0.22317851 & I & SI00 calcium binding protein AII \\
\hline BGN & 0.14883029 & I & Biglycan \\
\hline PRDX6 & 0.13666088 & I & Peroxiredoxin 6 \\
\hline LUM & 0.11588513 & I & Lumican \\
\hline $\mathrm{DCN}$ & 0.11182324 & 2 & Decorin \\
\hline TMSB4X & 0.09082789 & I & Thymosin beta 4 X-linked \\
\hline TAGLN & 0.08225353 & I & Transgelin \\
\hline HSPBI & 0.07331017 & 2 & Heat shock protein family B (small) member I \\
\hline CFLI & $0.073|459|$ & I & Cofilin I \\
\hline SOD3 & 0.06748032 & I & Superoxide dismutase 3 \\
\hline SERPINAI & 0.06422752 & I & Serpin family A member I \\
\hline TMSBIO & 0.06252222 & I & Thymosin beta 10 \\
\hline PEAI 5 & 0.06080867 & I & Proliferation and apoptosis adaptor protein 15 \\
\hline PTMA & 0.05742044 & 3 & Prothymosin alpha \\
\hline MIF & 0.05565778 & I & Macrophage migration inhibitory factor \\
\hline TAGLN2 & 0.05050489 & I & Transgelin 2 \\
\hline CNNI & $0.048|I| I \mid$ & I & Calponin I \\
\hline HSPE I & 0.04301032 & I & Heat shock protein family E (Hspl0) member I \\
\hline HMGN2 & 0.04088889 & I & High mobility group nucleosomal binding domain 2 \\
\hline AHSG & 0.03716489 & 2 & Alpha 2-HS glycoprotein \\
\hline GLG I & 0.03544518 & 1 & Golgi glycoprotein I \\
\hline PCNP & 0.0228 & I & PEST proteolytic signal containing nuclear protein \\
\hline LSM2 & 0.0208 & I & LSM2 homolog, U6 small nuclear RNA and mRNA degradation associated \\
\hline RPL6 & 0.0068 & I & Ribosomal protein L6 \\
\hline
\end{tabular}


going to become a promising research focus, attracting the attention of a large number of researchers. ${ }^{21}$ A number of researches have been performed to identify the endogenous peptides which participated in adiposity, ${ }^{32}$ preeclampsia, ${ }^{33}$ bronchopulmonary dysplasia, ${ }^{31}$ polycystic ovarian syndrome ${ }^{9}$ and, especially in cancer. ${ }^{34}$ These studies further revealed the pathogenesis of corresponding diseases and provided new ideas and choices for the diagnosis and treatment of these diseases. However, identification and further researches on peptides related to $\mathrm{BC}$ are still not been performed. Therefore, in order to develop new diagnostic markers and therapeutic targets, we conducted the present study to reveal the peptide expression profile of $\mathrm{BC}$.

When a protein is cleaved by a protease, a peptide fragment is produced. According to previous researches, the cleavage sites at the $\mathrm{N}$ - and $\mathrm{C}$-termini of endogenous peptides are highly conserved, despite differences in the sample preparation conditions used to analyze specific samples across individuals. In addition, the degradation of proteins and peptides varies greatly from disease to disease depending on the activity and species of their respective proteolytic enzymes. ${ }^{18,35}$ The cleavage sites in the peptides that were differentially expressed in our study are summarized in Figure 2D. The probability that any of these 20 amino acids are located at these four cleavage sites is very different. Because each protease has its own specific rules for cleavage of proteins, our results reveal that a distinct set of proteases is active in the progression of BC. This is worth our further study.

Previous studies have revealed that the functions of endogenous peptides are closely related to their precursor proteins. $^{36,37}$ Therefore, in order to further analyze the potential roles of these dysregulated peptides in $\mathrm{BC}$, we performed GO and KEGG pathway analysis based on their precursor proteins. As the most important enzyme in the cell, oxidoreductase mediates a large number of important life activities in the cell. In molecular function, we found that the dysregulated peptides were tightly associated with "oxidoreductase activity". Prasai et al have proved that oxidoreductase plays a crucial role in facilitated visualization and detection of human cancer cells. ${ }^{38}$ Meanwhile, as revealed by Hernandez-Fernaud et al, secreted CLIC3 can drive cancer progression through its glutathione-dependent oxidoreductase activity. ${ }^{39}$ These researches indicate that the differentially expressed peptides may participate in $\mathrm{BC}$ through their regulation of oxidoreductase activity. Meanwhile, in cellular component, many different secreted peptides and their precursor proteins are associated with extracellular matrix. Previous studies have revealed that extracellular matrix could play an important part in diagnosis and targeted therapy of cancer. ${ }^{40,41}$ Focal adhesion (FA) is a subcellular structure which provides strong adhesion to the extracellular matrix and acts as a scaffold for many signaling pathways involving integrin or the mechanical force exerted on cells. ${ }^{42}$ Recent studies have revealed the dynamic cycle of "FA assembly-cytoskeleton remodelling-FA disassembly", which allows cells to move, and the regulation of FA is considered an important step in tumor invasion. ${ }^{43,44}$ Furthermore, Kong et al have proved that the inhibition of focal adhesion kinase could induce apoptosis in BC cells via Src and the phosphatidylinositol 3-kinase/Akt pathway. ${ }^{45}$ In our analysis, a number of dysregulated peptides were found to be tightly related to focal adhesion, which indicates that these peptides may participate in $\mathrm{BC}$ invasion through the regulated of focal adhesion.

Endogenous peptides have been proved to play biological function closely associated with their precursor proteins. Proteins maintain a temporal and spatial coherence by forming a protein-protein-interaction (PPI) network while performing biological functions. By constructing an interaction network of differentially expressed proteins, we can find the trend of differentially expressed peptides from the proteome level, which further helps us to find key nodes in differentially expressed peptides. In the PPI analysis, we finally find UBA52, HSPE1, P4HB and RPS3A are the top four hub protein in the network. Previous studies have revealed that $\mathrm{P} 4 \mathrm{HB}$ played a crucial role in the progression of multiple malignant tumors, ${ }^{46,47}$ indicating that peptides derived from $\mathrm{P} 4 \mathrm{HB}$ protein may be the promising targets of the treatment of $\mathrm{BC}$.

A protein domain is a relatively conserved portion of a given protein sequence and structure and it exists, evolves, and functions independently of the rest of the protein chain. In order to find more potential bioactive peptides, we identified 36 peptide sequences located in the functional domains using the online tools SMART and UniProt. In addition, we further used the Open Target Platform database to explore the precursor proteins related to urogenital neoplasm. Previous researches have proved that these progenitor proteins are involved in BC. For example, SERPINA1 was revealed to be a urinary protein biomarker which could help us detect the $\mathrm{BC}$ in early stage. ${ }^{48,49}$ Rosser et al also found that SERPINA1 protein could be applied in the early diagnosis of $\mathrm{BC}$ 
recurrence. $^{50}$ These efforts have proved that peptides derived from SERPINA1 would be promising tumor diagnostic biomarkers. Meanwhile, $\mathrm{Wu}$ et al found that LGALS1 is associated with tumor invasiveness and is a possible independent prognostic marker of urinary bladder urothelial carcinoma. ${ }^{51}$ In addition, their further research revealed that LGALS1 could enhance urinary bladder urothelial carcinoma cell invasion through the JNK pathway. ${ }^{52}$ The functions of peptides are closely related to their precursor protein. ${ }^{36,37}$ Therefore, our results revealed that ${ }^{45}$ HFNPRFNAHGDAN ${ }^{57}$ derived from LGALS1 might play a crucial role in $\mathrm{BC}$ and could be the promising diagnostic biomarker and therapeutic target of $\mathrm{BC}$.

Several strengths were observed in the present study. First, we identified a series of peptides that are significantly differentially expressed in $\mathrm{BC}$, and these peptides may play a potential biological function in the progression of $\mathrm{BC}$. Based on our research, researchers can further reveal the pathogenesis of $\mathrm{BC}$ from the perspective of peptides. Secondly, peptidomics is currently not widely used in the field of BC. Our innovative study provides a methodological reference for future researchers. Finally, peptide drugs have been developed and used in the treatment of multiple diseases. Our research has laid the foundation for the development of peptide research in BC and the development of peptide drugs. However, follow-up studies are essential to validate the roles of the dysregulated peptides.

\section{Conclusion}

In the present study, we have identified and compared the peptidomic profiles of $\mathrm{BC}$ tissue and normal control and finally observed significantly different expression patterns. Our further analysis revealed that ${ }^{45}$ HFNPRFNAHGDAN 57 derived from LGALS1 and those peptides derived from P4HB and SERPINA1 might be the promising diagnostic biomarkers and therapeutic targets of BC. Our research provides us new insights into the pathogenesis mechanism of $\mathrm{BC}$ and could help us to discover novel biomarkers to better predict and prevent $\mathrm{BC}$.

\section{Abbreviation}

$\mathrm{BC}$, bladder cancer; NMIBC, non-muscle invasive $\mathrm{BC}$; MIBC, muscle invasive BC; TURBT, transurethral resection of bladder tumor; STEAP, six-transmembrane epithelial antigen of the prostate; DEPDC1, DEP domain containing 1; MPHOSPH1, and M-phase phosphoprotein
1; LC-MS/MS, liquid chromatography tandem mass spectrometry; TMT, tandem mass tag; GO, gene ontology; MWCO, molecular weight cut off; PPI, protein-protein interaction; pI, isoelectric point; STRING, the Search Tool for the Retrieval of Interacting Genes.

\section{Data Sharing Statement}

The datasets used or analyzed in the present study are available from the corresponding author on reasonable request.

\section{Acknowledgments}

The authors acknowledge the contribution of all investigators at the participating study sites.

\section{Funding}

This work was financially supported by the National Natural Science Foundation of China (81772712, 81702569), the Natural Science Foundation of Jiangsu Province (BK20170151).

\section{Disclosure}

The authors report no conflicts of interest for this work and declare that there is no duality of interest associated with this manuscript.

\section{References}

1. Antoni S, Ferlay J, Soerjomataram I, Znaor A, Jemal A, Bray F. Bladder cancer incidence and mortality: a global overview and recent trends. Eur Urol. 2017;71(1):96-108. doi:10.1016/j.eururo.2016.06. 010

2. Ferlay J, Soerjomataram I, Dikshit R, et al. Cancer incidence and mortality worldwide: sources, methods and major patterns in GLOBOCAN 2012. Int $J$ Cancer. 2015;136:E359-E386. doi:10.10 02/ijc. 29210

3. Kamat AM, Hahn NM, Efstathiou JA, et al. Bladder cancer. Lancet. 2016;388:2796-2810. doi:10.1016/s0140-6736(16)30512-8

4. Frantzi M, van Kessel KE, Zwarthoff EC, et al. Development and validation of urine-based peptide biomarker panels for detecting bladder cancer in a Multi-center Study. Clin Cancer Res. 2016;22: 4077-4086. doi:10.1158/1078-0432.Ccr-15-2715

5. Martin-Doyle W, Leow JJ, Orsola A, Chang SL, Bellmunt J. Improving selection criteria for early cystectomy in high-grade $\mathrm{t} 1$ bladder cancer: a meta-analysis of 15,215 patients. J Clin Oncol. 2015;33:643-650. doi:10.1200/jco.2014.57.6967

6. Babjuk $\mathrm{M}$, Burger $\mathrm{M}$, Zigeuner $\mathrm{R}$, et al. EAU guidelines on non-muscle-invasive urothelial carcinoma of the bladder: update 2013. Eur Urol. 2013;64:639-653. doi:10.1016/j.eururo.2013.06.003

7. Funt SA, Rosenberg JE. Systemic, perioperative management of muscle-invasive bladder cancer and future horizons. Nat Rev Clin Oncol. 2017;14:221-234. doi:10.1038/nrclinonc.2016.188

8. Sargos P, Baumann BC, Eapen L, et al. Risk factors for loco-regional recurrence after radical cystectomy of muscle-invasive bladder cancer: a systematic-review and framework for adjuvant radiotherapy. Cancer Treat Rev. 2018;70:88-97. doi:10.1016/j.ctrv.2018.07.011 
9. Jia G, Tao H, Xue Y, et al. Analysis of secreted peptidome from omental adipose tissue in polycystic ovarian syndrome patients. J Cell Physiol. 2018;233:5885-5894. doi:10.1002/jcp.26393

10. Baggerman G, Boonen K, Verleyen P, De Loof A, Schoofs L. Peptidomic analysis of the larval Drosophila melanogaster central nervous system by two-dimensional capillary liquid chromatography quadrupole time-of-flight mass spectrometry. J Mass Spectrom. 2005;40:250-260. doi:10.1002/jms.744

11. Shen C, Sun Z, Chen D, et al. Developing urinary metabolomic signatures as early bladder cancer diagnostic markers. Omics. 2015;19:1-11. doi:10.1089/omi.2014.0116

12. Azumi M, Kobayashi H, Aoki N, et al. Six-transmembrane epithelial antigen of the prostate as an immunotherapeutic target for renal cell and bladder cancer. $J$ Urol. 2010;183(5):2036-2044. doi:10.1016/j. juro.2009.12.094

13. Lehmann J, Retz M, Sidhu SS, et al. Antitumor activity of the antimicrobial peptide magainin II against bladder cancer cell lines. Eur Urol. 2006;50(1):141-147. doi:10.1016/j.eururo.2005. 12.043

14. Tsuruta M, Ueda S, Yew PY, et al. Bladder cancer-associated cancer-testis antigen-derived long peptides encompassing both CTL and promiscuous HLA class II-restricted Th cell epitopes induced $\mathrm{CD} 4+\mathrm{T}$ cells expressing converged T-cell receptor genes in vitro. Oncoimmunology. 2018;7(4):e1415687. doi:10.1080/2162402x.2017. 1415687

15. Villanueva J, Shaffer DR, Philip J, et al. Differential exoprotease activities confer tumor-specific serum peptidome patterns. $J$ Clin Invest. 2006;116:271-284. doi:10.1172/jci26022

16. Gemperline E, Keller C, Jayaraman D, et al. Examination of endogenous peptides in medicago truncatula using mass spectrometry imaging. J Proteome Res. 2016;15:4403-4411. doi:10.1021/acs. jproteome.6b00471

17. Tsuchiya $\mathrm{T}$, Iwakura $\mathrm{H}$, Minamino $\mathrm{N}$, Kangawa $\mathrm{K}$, Sasaki $\mathrm{K}$. Endogenous peptide profile for elucidating biosynthetic processing of the ghrelin precursor. Biochem Biophys Res Commun. 2017;490:1142-1146. doi:10.1016/j.bbrc.2017.06.155

18. Hu L, Ye M, Zou H. Recent advances in mass spectrometry-based peptidome analysis. Expert Rev Proteomics. 2009;6:433-447. doi:10.1586/epr.09.55

19. Czech H, Schepler C, Klingbeil S, Ehlert S, Howell J, Zimmermann R. Resolving coffee roasting-degree phases based on the analysis of volatile compounds in the roasting off-gas by Photoionization Time-of-Flight Mass Spectrometry (PI-TOFMS) and statistical data analysis: toward a PI-TOFMS roasting model. J Agric Food Chem. 2016;64:5223-5231. doi:10.1021/acs.jafc.6b01 683

20. Matsuzaki S, Darcha C, Maleysson E, Canis M, Mage G. Impaired down-regulation of E-cadherin and beta-catenin protein expression in endometrial epithelial cells in the mid-secretory endometrium of infertile patients with endometriosis. J Clin Endocrinol Metab. 2010;95:3437-3445. doi:10.1210/jc.2009-2713

21. Wang X, Xu S, Chen L, et al. Profiling analysis reveals the potential contribution of peptides to human adipocyte differentiation. Proteomics Clin Appl. 2018;12:e1700172. doi:10.1002/prca.2017 00172

22. von Mering C, Jensen LJ, Snel B, et al. STRING: known and predicted protein-protein associations, integrated and transferred across organisms. Nucleic Acids Res. 2005;33:D433-D437. doi:10.1093/nar/ gki005

23. Szklarczyk D, Franceschini A, Wyder S, et al. STRING v10: protein-protein interaction networks, integrated over the tree of life. Nucleic Acids Res. 2015;43:D447-D452. doi:10.1093/nar/ gku1003

24. Lone AM, Kim YG, Saghatelian A. Peptidomics methods for the identification of peptidase-substrate interactions. Curr Opin Chem Biol. 2013;17:83-89. doi:10.1016/j.cbpa.2012.10.038
25. Kim YG, Lone AM, Saghatelian A. Analysis of the proteolysis of bioactive peptides using a peptidomics approach. Nat Protoc. 2013;8:1730-1742. doi:10.1038/nprot.2013.104

26. Lis P, Dyląg M, Niedźwiecka K, et al. The HK2 dependent "warburg effect" and mitochondrial oxidative phosphorylation in cancer: targets for effective therapy with 3-bromopyruvate. Molecules. 2016;21. doi:10.3390/molecules 21121730

27. LeBleu VS, O'Connell JT, Gonzalez Herrera KN, et al. PGC-1 $\alpha$ mediates mitochondrial biogenesis and oxidative phosphorylation in cancer cells to promote metastasis. Nat Cell Biol. 2014;16:992-1003, 1-15. doi:10.1038/ncb3039

28. Geng RX, Li N, Xu Y, et al. Identification of core biomarkers associated with outcome in Glioma: evidence from bioinformatics analysis. Dis Markers. 2018;2018:3215958. doi:10.1155/2018/ 3215958

29. Argaw A, Duff G, Zabouri N, et al. Concerted action of CB1 cannabinoid receptor and deleted in colorectal cancer in axon guidance. $J$ Neurosci. 2011;31:1489-1499. doi:10.1523/jneurosci.41 34-09.2011

30. Li Y, Liu X, Tang H, Yang H, Meng X. RNA sequencing uncovers molecular mechanisms underlying pathological complete response to chemotherapy in patients with operable breast cancer. Med Sci Monit. 2017;23:4321-4327. doi:10.12659/msm.903272

31. Yin J, Wang X, Zhang L, et al. Peptidome analysis of lung tissues from a hyperoxia-induced bronchopulmonary dysplasia mouse model: insights into the pathophysiological process of bronchopulmonary dysplasia. J Cell Physiol. 2018;233:7101-7112. doi:10.1002/ jcp. 26633

32. Gao Y, Wang X, Huang F, et al. Identification and characterization of metformin on peptidomic profiling in human visceral adipocytes. $J$ Cell Biochem. 2018;119:1866-1878. doi:10.1002/jcb.26347

33. Qian Y, Zhang L, Rui C, et al. Peptidome analysis of amniotic fluid from pregnancies with preeclampsia. Mol Med Rep. 2017;16: 7337-7344. doi:10.3892/mmr.2017.7582

34. Moody TW. Peptide hormones and lung cancer. Panminerva Med. 2006;48:19-26.

35. Wang F, Zhu J, Hu L, Qin H, Ye M, Zou H. Comprehensive analysis of the $\mathrm{N}$ and $\mathrm{C}$ terminus of endogenous serum peptides reveals a highly conserved cleavage site pattern derived from proteolytic enzymes. Protein Cell. 2012;3:669-674. doi:10.1007/s13238-0122934-4

36. Haslam DW, James WP. Obesity. Lancet. 2005;366:1197-1209. doi:10.1016/s0140-6736(05)67483-1

37. Kawaguchi T, Yamagishi SI, Sata M. Structure-function relationships of PEDF. Curr Mol Med. 2010;10:302-311. doi:10.2174/1566524 10791065255

38. Prasai B, Silvers WC, McCarley RL. Oxidoreductase-facilitated visualization and detection of human cancer cells. Anal Chem. 2015;87:6411-6418. doi:10.1021/acs.analchem.5b01615

39. Hernandez-Fernaud JR, Ruengeler E, Casazza A, et al. Secreted CLIC3 drives cancer progression through its glutathione-dependent oxidoreductase activity. Nat Commun. 2017;8:14206. doi:10.1038/ ncomms 14206

40. van der Steen SC, Raave R, Langerak S, et al. Targeting the extracellular matrix of ovarian cancer using functionalized, drug loaded lyophilisomes. Eur J Pharm Biopharm. 2017;113:229-239. doi:10.10 16/j.ejpb.2016.12.010

41. Andriani F, Landoni E, Mensah M, et al. Diagnostic role of circulating extracellular matrix-related proteins in non-small cell lung cancer. BMC Cancer. 2018;18:899. doi:10.1186/s12885-018-4772-0

42. Burridge K. Focal adhesions: a personal perspective on a half century of progress. FEBS J. 2017;284:3355-3361. doi:10.1111/ febs. 14195

43. Carragher NO, Frame MC. Focal adhesion and actin dynamics: a place where kinases and proteases meet to promote invasion. Trends Cell Biol. 2004;14:241-249. doi:10.1016/j.tcb.2004.03.011 
44. Paluch EK, Aspalter IM, Sixt M. Focal adhesion-independent cell migration. Annu Rev Cell Dev Biol. 2016;32:469-490. doi:10.1146/ annurev-cellbio-111315-125341

45. Kong D, Chen F, Sima NI. Inhibition of focal adhesion kinase induces apoptosis in bladder cancer cells via Src and the phosphatidylinositol 3-kinase/Akt pathway. Exp Ther Med. 2015;10:17 25-1731. doi:10.3892/etm.2015.2745

46. Sun S, Lee D, Ho AS, et al. Inhibition of prolyl 4-hydroxylase, beta polypeptide $(\mathrm{P} 4 \mathrm{HB})$ attenuates temozolomide resistance in malignant glioma via the endoplasmic reticulum stress response (ERSR) pathways. Neuro Oncol. 2013;15:562-577. doi:10.1093/neuonc/not 005

47. Zhou Y, Yang J, Zhang Q, et al. P4HB knockdown induces human HT29 colon cancer cell apoptosis through the generation of reactive oxygen species and inactivation of STAT3 signaling. Mol Med Rep. 2019;19:231-237. doi:10.3892/mmr.2018.9660
48. Chen LM, Chang M, Dai Y, et al. External validation of a multiplex urinary protein panel for the detection of bladder cancer in a multicenter cohort. Cancer Epidemiol Biomarkers Prev. 2014;23:1804-1812. doi:10.1158/1055-9965.Epi-14-0029

49. Linden M, Segersten U, Runeson M, et al. Tumour expression of bladder cancer-associated urinary proteins. BJU Int. 2013;112: 407-415. doi:10.1111/j.1464-410X.2012.11653.x

50. Rosser CJ, Chang M, Dai Y, et al. Urinary protein biomarker panel for the detection of recurrent bladder cancer. Cancer Epidemiol Biomarkers Prev. 2014;23:1340-1345. doi:10.1158/1055-9965.Epi-14-0035

51. Wu TF, Li CF, Chien LH, et al. Galectin-1 dysregulation independently predicts disease specific survival in bladder urothelial carcinoma. JUrol. 2015;193:1002-1008. doi:10.1016/j.juro.2014.09.107

52. Shen KH, Li CF, Chien LH, et al. Role of galectin-1 in urinary bladder urothelial carcinoma cell invasion through the JNK pathway. Cancer Sci. 2016;107:1390-1398. doi:10.1111/cas.13016

\section{Publish your work in this journal}

OncoTargets and Therapy is an international, peer-reviewed, open access journal focusing on the pathological basis of all cancers, potential targets for therapy and treatment protocols employed to improve the management of cancer patients. The journal also focuses on the impact of management programs and new therapeutic agents and protocols on patient perspectives such as quality of life, adherence and satisfaction. The manuscript management system is completely online and includes a very quick and fair peer-review system, which is all easy to use. Visit http://www.dovepress.com/ testimonials.php to read real quotes from published authors. 